\title{
Convalescent Plasma Therapy: a Possible Treatment of COVID- 19 Pandemic
}

Shubha Devi Sapkota ${ }^{1 *}$, Monika Sharma², Gehendra Bhusal ${ }^{3}$

\author{
Author Info: \\ ${ }^{1} \mathrm{NPI}$-Narayani Samudayik \\ Hospital, College of Nursing, \\ Purbanchal University, \\ Chitwan, Nepal \\ 2Padmashree School of \\ Public Health, Rajiv Gandhi \\ University of Health Science, \\ Karnataka, India \\ ${ }^{3}$ Chitwan Medical College, \\ Tribhuvan University, Chitwan, \\ Nepal
}

\section{*Corresponding Author:}

Ms. Shubha Sapkota

Email/Contact:

shubhasapkota@gmail.com 09779845500600

ORCiD: https://orcid. org/0000-0001-8115-8042

\begin{abstract}
COVID 19 is a newly recognized infectious disease that has rapidly spread with no verified treatment available. It is caused by Severe Acute Respiratory Syndrome Coronavirus 2 (SARS-COV-2). In Convalescent plasma therapy, the yellowish liquid or the plasma from the recovered blood is used to treat the patient suffering from the same illness. For more than 100 years it has been used to treat severe infections with varying degrees of success. For this present infection, multiple clinical trials on plasma therapy are still under vigorous investigations. Despite the very low chance of risks like allergies, lung damage, and transmission of bloodrelated infection, the therapy has shown a positive result in the recovery of the patients. Many experts are observing its use as a "stopgap measure" until effective vaccines and antiviral drugs are available in a wide range. However, the main challenges faced are finding suitable donors, its expensiveness in the whole procedure, and inability to perform on a large scale. In this commentary, summarization of the convalescent plasma therapy is done as a hopeful alternative therapy of severe or critical COVID 19. It has also emphasized the promising results shown since the past while the use of this therapy in various infectious diseases.
\end{abstract}

Keywords: Convalescent Plasma Therapy, Treatment of COVID-19, Pandemic in Nepal

\begin{tabular}{|l|l|}
\hline QR Code & \multicolumn{1}{c|}{ Article Info } \\
\hline
\end{tabular}




\section{BACKGROUND}

The world seems to be vulnerable in the face of the COVID - 19 pandemics, with over 8.2 million cases already and over 445,000 deaths till June 19, 2020. ${ }^{1}$ Scientists all around the globe are working conscientiously to develop the preventable vaccine and to determine the efficacy of many drugs currently available including antivirals, protease inhibitors, nucleotide analog, and interleukin inhibitors. ${ }^{2}$ Apart from these, convalescent plasma transfusion is another treatment modality under investigation for its efficacy while treating severe patients.

\section{MAIN TEXT}

Convalescent plasma therapy is an experimental treatment modality that uses antibodies found in the bloodstream of the people who've recovered from infection for treating infected patients. In this phenomenon, the serum is separated from the blood drawn from the recovered person and screened for virus-neutralizing antibodies. ${ }^{3}$

Previously in the late 1800s, the convalescent blood product was used to treat infectious disease, firstly in treating diphtheria. Meanwhile in 19181920 during the Spanish influenza pandemic, the therapeutic regimen was studied. Later it was used widely to treat different infectious diseases like pneumococcal pneumonia and scarlet fever by the 1930s. Although, by the middle of the $20^{\text {th }}$ century, with the development of antimicrobials, its use declined. ${ }^{4,2}$ Whenever new epidemics or pandemics emerge, the use of passive antibody therapy has been renewed e.g., in previous corona virus outbreaks like SARS in 2002-04 and MERS in 2012. These positive results guided $\mathrm{WHO}$ in publishing guidelines on the use of the treatment modality for the Ebola virus. Simultaneously, the treatment results have shown a progressive decline in mortality of patients with severe pandemic influenza A virus (H1N1 2009). ${ }^{5}$ Even so, exact clinical evidence exhibiting the efficacy of the therapy is scanty.

During the current pandemic, in China, two small studies were done using convalescent plasma therapy, one an uncontrolled case series of five critical patients on mechanical ventilation, and the other, pilot study in ten severe COVID-19 patients. Consequently, the therapy showed sound results with improvement in a clinical outcome like fever, chest pain, cough, and shortness of breathing within 1-3 days of treatment. ${ }^{6,7}$
Likewise, a randomized clinical trial was performed including 103 patients, standard treatment with convalescent plasma $(n=52)$ against a control group of standard treatment alone $(n=51)$. In this clinically improved result was shown in 28 days with $51.9 \%$ in convalescent plasma group vs $43.1 \%$ in the standard treatment only group. This trial was terminated early because of the hazard ratio, 1.40, and was not statistically significant. ${ }^{8}$

Furthermore, a study in Texas, USA showed positive results on 25 severe or life-threatening COVID patients who were transfused with convalescent plasma. Gradually by $14^{\text {th }}$ post-transfusion day, there were at least one-point improvement on their clinical status in 19 (76\%) patients while 11 of them were discharged. ${ }^{9}$ Convalescent plasma therapy if started initially can help discontinue viral shedding and extend the patient's survival rate in critical COVID-19.10,11 Similarly, a decrease in mortality rate was seen in the USA in 5,000 hospitalized patients with severe or life-threatening COVID-19 after convalescent plasma therapy. ${ }^{12}$

The plasma donated by the people who have recovered from COVID-19 having a high concentration of anti-SARS-CoV-2 antibodies determines the success of convalescent plasma therapy. The donor and the patient must have compatible blood types and no signs of multiple diseases, including COVID-19, Hepatitis, and HIV. ${ }^{3}$ Many treatment regimens were under trial and few were promising too. Despite that, it might be too early to decide on any result of valid clinical trials. ${ }^{13,} 14$ Finding suitable donors and conducting tests to confirm sufficient antibody levels in plasma are likely the main challenges for health care providers. Likewise, blood transfusion reactions, another potential complication is the transmission of unknown pathogens and infection risk to laboratory personnel processing the plasma.

\section{CONCLUSION}

Hence, convalescent plasma therapy is considered as a safe treatment option for treating patients with severe COVID-19 disease after different studies showed favoring results. Although, it's too early to jump to any conclusion so further randomized clinical trials are recommended on a larger scale for its efficacy.

Authors' contributions: SDS has contributed to conceptualizing and writing of the first draft of the 
manuscript. All the authors have put their input in critically reviewing and finalizing the manuscript.

Acknowledgements: We apologize to the authors whose work has not been cited here due to space limitations.

\section{REFERENCES}

1. WHO Coronavirus Disease (COVID-19) Dashboard. Accessed on 19 June 2020. [Link]

2. Schnur MB. Convalescent Plasma Therapy- Is It a Viable Treatment for COVID- 19. Lippincott Nursing Center.2020. Assessed 18 April 2020. [Link]

3. Shah DR. Plasma therapy: New hope for COVID 19 The Himalayan Times.2020. Assessed 09 April 2020, [Link]

4. Marano G, Vaglio S, Pupella S, Facco G, Catalano L, Liumbruno GM, Grazzini G. Convalescent plasma: new evidence for an old therapeutic tool? Blood Transfusion. 2016;14(2):152. DOI: https://dx.doi. org/10.2450\%2F2015.0131-15 [PMC]

5. Chen L, Xiong J, Bao L, Shi Y. Convalescent plasma as a potential therapy for COVID-19. The Lancet Infectious Diseases. 2020;20(4):398-400. https://doi. org/10.1016/S1473-3099(20)30141-9

6. Haematology TL. The resurgence of convalescent plasma therapy. The Lancet. Haematology. 2020;7(5):e353. DOI: https://doi.org/10.1016/ \$2352-3026(20)30117-4, [PMC

7. Duan K, Liu B, Li C, Zhang H, Yu T, Qu J, Zhou M, Chen L, Meng S, Hu Y, Peng C. Effectiveness of convalescent plasma therapy in severe COVID-19 patients. Proceedings of the National Academy of Sciences. 2020;117(17):9490-6. https://doi. org/10.1073/pnas.2004168117
8. Li L, Zhang W, Hu Y, Tong X, Zheng S, Yang J, Kong Y, Ren L, Wei Q, Mei H, Hu C. Effect of Convalescent Plasma Therapy on Time to Clinical Improvement in Patients with Severe and Life-threatening COVID-19: A Randomized Clinical Trial. Jama. 2020. https://doi. org/10.1001/jama.2020.10044 [Link]

9. Salazar E, Perez KK, Ashraf M, Chen J, Castillo B, Christensen PA, Eubank T, Bernard DW, Eagar TN, Long SW, Subedi S. Treatment of COVID-19 Patients with Convalescent Plasma. The American Journal of Pathology. 2020. https://doi.org/10.1016/j. ajpath.2020.05.014 Retrieved [Link]

10. Zeng QL, Yu ZJ, Gou JJ, Li GM, Ma SH, Zhang GF, Xu JH, Lin WB, Cui GL, Zhang MM, Li C. Effect of convalescent plasma therapy on viral shedding and survival in patients with coronavirus disease 2019. The Journal of infectious diseases. 2020;222(1):3843. https://doi.org/10.1093/infdis/jiaa228

11. Zhang B, Liu S, Tan T, Huang W, Dong Y, Chen L, Chen Q, Zhang L, Zhong Q, Zhang X, Zou Y. Treatment with convalescent plasma for critically ill patients with SARS-CoV-2 infection. Chest. 2020. DOI: https://doi. org/10.1016/j.chest.2020.03.039 [Link]

12. Joyner $M J$, Wright RS, Fairweather $D$, Senefeld JW Bruno KA, Klassen SA, Carter RE, Klompas AM, Wiggins CC, Shepherd JR, Rea RF. Early safety indicators of COVID-19 convalescent plasma in 5,000 patients. The Journal of Clinical Investigation. 2020. DOI: https://doi.org/10.1172/JCl140200 [Link]

13. Cunningham AC, Goh HP, Koh D. Treatment of COVID-19: old tricks for new challenges. Critical Care 2020; 24:91. DOI: https://doi.org/10.1186/ s13054-020-2818-6

14. Rajendran K, Narayanasamy K, Rangarajan J Rathinam J, Natarajan M, Ramachandran A. Convalescent plasma transfusion for the treatment of COVID-19: Systematic review. Journal of Medical Virology. 2020. DOI: https://doi.org/10.1002/ jmv.25961 [Link] 